\title{
Korunga (Onobrychis viciifolia) Hipokotil Eksplantlarının In Vitro Rejenerasyon Yeteneğinin Be- lirlenmesi
}

\author{
Determination of In Vitro Regeneration Ability of Sainfoin (Onobrychis viciifolia) \\ Hypocotyl Explants
}

\section{Hüseyin UYSAL ${ }^{1 *}$ \\ Tuğba TOPBAŞ ${ }^{1}$}

${ }^{1}$ Aydın Adnan Menderes Üniversitesi, Ziraat

Fakültesi, Tarımsal Biyoteknoloji Bölümü, Aydın

\section{ORCID}

iD 0000-0002-7039-4725

iD 0000-0003-2501-7282

\section{*Sorumlu yazar:}

huseyin.uysal@adu.edu.tr

\section{ÖZET}

$\mathrm{Bu}$ araşırıma Korunga (Onobrychis viciifolia Scop.) Özerbey-03 çeşidine ait hipokotil eksplantlarının BAP (6-Benzil Amino Pürin- sitokinin hormonu) ve İAA (İndol-3-Asetik Asit- oksin hormonu) içeren besi ortamlarındaki gelişimini araştırmak amacıyla gerçekleştirilmiştir. Araştırmada temel besi ortamı olarak MS (Murashige and Skkog) besi ortamı kullanılmış olup bu ortama $0.5 \mathrm{mg} . \mathrm{l}^{-1}$ BAP ve IAA ayrı ayrı ilave edilmiş, yine kullanılan temel besi ortamına $0.5 \mathrm{mg} \cdot \mathrm{l}^{-1} \mathrm{BAP}+0.5 \mathrm{mg} . \mathrm{l}^{-1}$ IAA, $0.5 \mathrm{mg} . \mathrm{l}^{-1} \mathrm{BAP}+0.1 \mathrm{mg} . \mathrm{l}^{-1} \mathrm{IAA}$ ve $0.1 \mathrm{mg} . \mathrm{l}^{-1} \mathrm{BAP}+0.5$ mg..$^{-1}$ IAA oranlarında sitokinin ve oksin hormonları birlikte ilave edilmiştir. Araştırma sonucunda direk rejenerasyon bakımından hiçbir hormon kullanılmayan yalın ortamının en iyi sonucu (\%84) verdiği, kallus oluşumu bakımından ise $0.5 \mathrm{mg} . \mathrm{l}^{-1} \mathrm{BAP}+0.1 \mathrm{mg} \cdot \mathrm{l}^{-1} \mathrm{IAA}$ içeren ortamın en iyi sonucu (\%84) verdiği, besi ortamları toplam rejenerasyon bakımından değerlendirildiğinde ise en iyi sonucu (\%100) 0.5 mg..$^{-1}$ BAP + $0.1 \mathrm{mg} \cdot \mathrm{l}^{-1} \mathrm{IAA}$ ve $0.1 \mathrm{mg} . \mathrm{l}^{-1} \mathrm{BAP}+0.5 \mathrm{mg} \cdot \mathrm{l}^{-1} \mathrm{IAA}$ içeren besi ortamlarının verdiği belirlenmiştir. Ayrıca kalluslardan sürgün rejenerasyonu bakımından en iyi sonuç ( 0.83 adet/kallus) 0.5 mg. ${ }^{-1}$ BAP içeren ortamdan elde edilmiştir. Bu araştırmanın genel sonucu olarak korunga bitkisinde direk rejenrasyon açısından hormon içermeyen besi ortamlarının, kallus oluşumu açısından ise yüksek konsantrasyonda BAP içeren ve BAP + İAA içeren besi ortamlarının tercih edilmesi başarı oranını arttıracağı söylenebilir.
Gönderilme Tarihi: $\quad 1$ Mart 2021

Kabul Tarihi ～: 15 Mayıs 2021 
Anahtar Kelimeler: Korunga, Onobrychis viciifolia,in vitro, oksin, sitokinin

\section{ABSTRACT}

This study was carried out to investigate the development of hypocotyl explants of the sainfoin (Onobrychis viciifolia Scop.) Özerbey-03 variety in nutrient media containing BAP (6-benzyl amino purine-cytokinin hormone) and IAA (3-indole acetic acid-auxin hormone). In the study, MS (Murashige and Skkog) medium was used as the main medium and $0.5 \mathrm{mg} \cdot \mathrm{l}^{-1} \mathrm{BAP}$ and IAA were added separately, and the cytokinin and the auxin hormones were added together in the ratio of $0.5 \mathrm{mg} . \mathrm{l}^{-1} \mathrm{BAP}+0.5 \mathrm{mg} . \mathrm{l}^{-1}$ IAA, $0.5 \mathrm{mg} \cdot \mathrm{l}^{-1} \mathrm{BAP}+0.1 \mathrm{mg} \cdot \mathrm{l}^{-1} \mathrm{IAA}$ and $0.1 \mathrm{mg} . \mathrm{l}^{-1} \mathrm{BAP}$ $+0.5 \mathrm{mg} \cdot \mathrm{l}^{-1} \mathrm{IAA}$ to this medium. As a result of the study, it was determined that the best result (84\%) was gained in terms of direct regeneration from the medium without using any hormones, and the best result (84\%) was gained in terms of callus formation from the medium containing $0.5 \mathrm{mg} . \mathrm{l}^{-1} \mathrm{BAP}+0.1 \mathrm{mg} \cdot \mathrm{l}^{-1} \mathrm{IAA}$, when the mediums are evaluated in terms of the total regeneration, the best result (100\%) was given by the medium containing $0.5 \mathrm{mg} .1$ ${ }^{1} \mathrm{BAP}+0.1 \mathrm{mg} . \mathrm{l}^{-1} \mathrm{IAA}$ and $0.1 \mathrm{mg} . \mathrm{l}^{-1} \mathrm{BAP}+0.5 \mathrm{mg} . \mathrm{l}^{-}$ ${ }^{1}$ IAA. In addition, the best result ( 0.83 pcs / callus) in terms of shoot regeneration from calluses was obtained

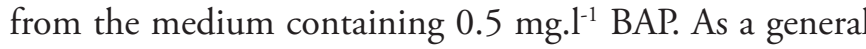
result of this research, it can be said that the preference of hormone-free medium for direct regeneration and the medium containing high concentrations of BAP and BAP + IAA in terms of callus formation will increase the success rate in sainfoin plants.

Keywors: Sainfoin, Onobrychis viciifolia, in vitro, auxin, cytokinin

\section{GİISS}

Korunga (Onobrychis viciifolia Scop. Syn., Onobrychis sativa Lam.) Angiospermae (kapalı tohumlular)'ın Dicotyledonae (iki çenekliler) sınıfı, Rosales takımının Leguminosae (baklagiller) familyasının Papilionoidae alt familyası içinde yer almaktadır (İleri, 2014). Onobrychis cinsinin geçerli adı ilk kez Miller tarafından verilmiştir. Linne bu cinse ait türleri 1753 yılında Hedysarum cinsi içerisinde yer vermiştir. Sonradan bu türler Onobrychis cinsine aktarılmıştır. Türkiye korunga türleri ile ilgili bilgiler birçok türü tanımlayan Boissier'in (1872) Flora Orientalis adlı eserinde yer almaktadır. Sonraki yıllarda Türkiye türleri ile ilgili yapılan en kapsamlı çalışma Hedge'nin (1970) Türkiye florası için yaptığı revizyonudur.

Dünyada korunga (Onobrychis) cinsine bağlı 162 tür bilinmekte olup bunlar içerisinde sadece 3 tür, [Yaygın korunga (Onobrcyhis sativa Lam.), Anadolu korungası (Onobrychis arenaria K.) ve Kafkas korungası (Onobrychis transcaucacia G.)] tarımsal açıdan önem taşımaktadır (Yücel, 2019). Türkiye'de ise Onobrychis cinsine giren 53 farklı türün dahil olduğu 60 adet tür, alttür ve varyete bulunmaktadır. Bunların içerisinde 11 adedi alttür ve varyete düzeyinde olmak üzere toplam 35 adedi endemiktir (Anonim, 2021).

Yoncada tanin maddesi bulunmadığı için özellikle taze tüketimde hayvanlarda şişmelere sebebiyet vermektedir. Korungada ise tanin maddesi bulunduğu için korunga hayvanlarda şişme yapmaz ve protein içerikli iyi bir kaba yem kaynağıdır. Ayrıca toprak ıslahı açısından büyük önem taşımaktadır (Yücel, 2019). Gösterişli çiçeklerinde bol miktarda nektar bulunması nedeni ile arıcılık ve bal üretimi açısından da son derece önemli bir bitkidir (Özbek, 2011). Baklagil yem bitkisi olması nedeniyle de simbiyotik fiksasyonla havanın serbest azotunu bağlayarak toprağın azotça zenginleşmesini sağlamaktadır (Beyaz, 2014).

Günümüze kadar pek çok korunga türünde in vitro doku ve hücre kültürü teknikleriyle rejenerasyon sağlanmıştır (Özcan vd., 1996; Sancak, 1999; Mohajer vd., 2012; Yıldız ve Ekiz, 2014; Uzun ve Yükselgüngör, 2020). Ancak in vitro kültürlerde başarı başta genotip ve besi ortamının bileşimi olmak üzere, çeşitli genetik, fiziksel ve kimyasal faktörler tarafından belirlenmektedir. Son yarım yüzyılda geleneksel ıslah yöntemlerine ilave edilen in vitro teknikler sayesinde etkili ve kısa sürede sonuçların alınması sağlanmaktadır. Bu teknikler sayesinde birçok bitkide tarımsal açıdan başarılı sonuçlar elde edilmiştir (Kurt, 2015). Ancak Dünyada bitki ıslahında biyoteknolojik devrim yaşanmasına rağmen biyoteknolojik uygulamalar korunga ıslahı çalışmalarına 
yeterince yansımamıştır. $\mathrm{Bu}$ yüzden bu bitki üzerinde yapılacak her türlü biyoteknolojik uygulama önem arz etmektedir. $\mathrm{Bu}$ tekniklerden klonal çoğaltım tekniği; bitki doku kültürü uygulamalarında başta mikro çoğaltım olmak üzere birçok kullanım alanı bulmuştur. Özellikle gen transfer çalışmalarının temelini oluşturan klonal çoğaltım; heterozigot genotiplerin çoğaltımı, tohumla çoğalamayan bitkilerin çoğaltımı, erkek kısır hatların çoğaltımı, hastalıksız bitkilerin çoğaltımı gibi amaçlarla kullanılmaktadır (Hatipoğlu, 2012).

$\mathrm{Bu}$ çalışma ile çeşitli oksin ve sitokinin hormonları kullanılarak korunga bitkisinde etkin bir klonal çoğaltım protokolünün oluşturulması amaçlanmıştır.

\section{MATERYAL VE YÖNTEM}

Bu araştırma Aydın Adnan Menderes Üniversitesi (ADÜ), Ziraat Fakültesi, Tarımsal Biyoteknoloji Bölümü Doku Kültürü Laboratuvarında yürütülmüştür. Araştırmada bitki materyali olarak Özerbey-03 Korunga çeşidine ait hipokotil eksplantları kullanılmıştır. Araştırmada MS (Murahige and Skoog) besi ortamı (Çizelge 1) ve bu ortamın 5 farklı konsantrasyonda BAP (6-Benzil Amino Pürin) ve İAA (Indol-3- Asetik Asit) hormonları ile desteklenmiş 6 farklı versiyonu kullanılmıştır (Çizelge 2). Araştırmada kullanılan besi ortamları hazırlanırken önce stok solüsyonları daha sonra bu stok solüsyonlarından besi ortamları hazırlanmıştır. Stok solüsyonları hazırlanırken makro elementler kendi içerisinde, mikro elementler kendi içerisinde, Fe ve $\mathrm{Na}_{2}$-EDTA kendi içerisinde beraber; $\mathrm{KI}$, her bir vitamin ve bitki büyüme düzenleyicisi de ayrı ayrı stok olacak şekilde hazırlanmıştır. Stok solüsyonları hazırlanırken BAP ve IAA 2-3 ml $1 \mathrm{~N} \mathrm{NaOH}$ içerisinde çözdürüldükten sonra hacimleri distile su ile normal hacimlerine tamamlanmıştır. Myo inositol ve şeker her seferinde ayrıca tartılarak besi ortamına ilave edilmiştir. Besi ortamlarının PH'sı 5.8 olacak şekilde ayarlandıktan sonra agar ilave edilerek otoklavda $121{ }^{\circ} \mathrm{C}$ 'de 15 dakika süre ile sterilize edilmiştir. Steril hale getirilen besi ortamları yaklaşık $50{ }^{\circ} C^{\prime}$ ye soğuduktan sonra biyogüvenlik kabini içerisinde $9 \mathrm{~cm}$ çapındaki steril petri kaplarına her bir petride $25 \mathrm{ml}$ olacak şekilde dökülmüştür. Besi ortamları katılaştıktan sonra streç filmlerle sarılarak kullanılıncaya kadar oda sıcaklığında bekletilmiştir. Besi ortamları mümkün olduğunca taze olarak hazırlanmış ve hazırlanan besi ortamları 15 gün içerisinde tüketilmiştir.

Araştırmada kullanılan korunga tohumlarının meyve kabukları çıkarıldıktan sonra tohumlar biyogüvenlik kabini içerisinde önce 30 saniye süre ile \%70'lik etil alkolle ön sterilizasyona tabi tutulmuş, sonrasında 10 dakika süre

Çizelge 1. Çalışmada kullanılan MS besi ortamının içeriği

\begin{tabular}{|c|c|}
\hline Kimyasal Madde & $\operatorname{Miktar}\left(\mathbf{m g . l ^ { - 1 }}\right)$ \\
\hline $\mathrm{KNO}_{3}$ & 1900 \\
\hline $\mathrm{CaCl}_{2} \cdot \mathrm{H}_{2} \mathrm{O}$ & 332.2 \\
\hline $\mathrm{NH}_{4} \mathrm{NO}_{3}$ & 1650 \\
\hline $\mathrm{MgSO}_{4} \cdot 7 \mathrm{H}_{2} \mathrm{O}$ & 180.7 \\
\hline $\mathrm{KH}_{2} \mathrm{PO}_{4}$ & 170 \\
\hline $\mathrm{Na}_{2}$-EDTA & 37.25 \\
\hline $\mathrm{FeSO}_{4} \cdot 7 \mathrm{H}_{2} \mathrm{O}$ & 27.85 \\
\hline $\mathrm{H}_{3} \mathrm{BO}_{3}$ & 6.2 \\
\hline $\mathrm{MnSO}_{4} \cdot \mathrm{H}_{2} \mathrm{O}$ & 16.9 \\
\hline $\mathrm{ZnSO}_{4} \cdot 7 \mathrm{H}_{2} \mathrm{O}$ & 8.6 \\
\hline KI & 0.83 \\
\hline $\mathrm{Na}_{2} \mathrm{MoO}_{4} \cdot \mathrm{H}_{2} \mathrm{O}$ & 0.25 \\
\hline $\mathrm{CuSO}_{4} .5 \mathrm{H}_{2} \mathrm{O}$ & 0.025 \\
\hline $\mathrm{CoCl}_{2} \cdot 6 \mathrm{H}_{2} \mathrm{O}$ & 0.025 \\
\hline Glycin & 2.0 \\
\hline Myo-Inostol & 100 \\
\hline Nicotinic asit & 0.5 \\
\hline Pyrodoxine- $\mathrm{HCl}$ & 0.5 \\
\hline Thiamin HCI & 0.1 \\
\hline Sukroz & 30000 \\
\hline Agar & 7000 \\
\hline $\mathrm{PH}$ & 5.8 \\
\hline
\end{tabular}

Çizelge 2. Araştırmada kullanılan besi ortamına ilave edilen BAP ve IAA konsantrasyonları

\begin{tabular}{|c|c|c|}
\hline Besi Ortamı No & $\mathrm{BAP}\left(\mathrm{mg.l}^{-1}\right)$ & $\operatorname{IAA}\left(\mathrm{mg} \mathbf{l}^{-1}\right)$ \\
\hline MS1 & - & - \\
\hline MS2 & 0.5 & - \\
\hline MS3 & - & 0.5 \\
\hline MS4 & 0.5 & 0.5 \\
\hline MS5 & 0.5 & 0.1 \\
\hline MS6 & 0.1 & 0.5 \\
\hline
\end{tabular}


ile \%20'lik ticari çamaşır suyu (ACE) çözeltisi ile muamele edilmiş ve arkasından 3-5 kez steril su ile durulama yapılarak steril hale getirilmiştir. Steril edilen tohumların çimlendirilmesi hormon içermeyen MS besi ortamında gerçekleştirilmiştir. Ekim sonrası petriler $25^{\circ} \mathrm{C}$ ve 16 saat aydınlık 8 saat karanlık fotoperiyoda sahip iklimlendirme odasında kültüre alınmıştır.

Çimlenme sonrası hipokotiller yaklaşık 2-3 cm boya ulaştıklarında biyogüvenlik kabini içerisinde yaklaşık $0.5 \mathrm{~cm}$ boyutlarında kesilerek Çizelge 2'de belirtilen besi ortamlarında kültüre alınmıştır. Eksplantlar her bir besi ortamı için 5 adet petri ve her petride 10 adet bitki eksplantı olacak şekilde kültüre alınarak iklimlendirme odasında gelişmeye bırakılmıştır.

Araştırma kapsamında kültüre alınan meristemlerde elde edilen tam bitki sayıları, direk rejenere sürgün ve kök sayıları, elde edilen kallus sayıları, kalluslardan elde edilen sürgün sayıları gün aşırı yapılan kontrollerle belirlenerek kaydedilmiştir.

Araştırma tesadüf parselleri deneme desenine göre kurulmuş olup, besi ortamında gelişim 4 haftalık sürenin sonunda değerlendirilmiştir. Sonuçlar varyans analizine tabi tutulmuş ve Duncan çoklu karşılaştırma testi ile istatistiki olarak değerlendirilmiştir.

\section{BULGULAR VE TARTIŞMA}

$\mathrm{Bu}$ araştırmada kültüre alınan hipokotil eksplantlarından elde edilen direk rejenerasyon sayıları ve başarı oranlarına ilişkin veriler Çizelge 3'de verilmiştir.

Kültüre alınan eksplantlardan direk rejenerasyon bakımından en yüksek başarı oranı \%84 ile yalın besi ortamından elde edilmiştir. Bu ortamda kültüre alınan 50 eksplanttan 42'si direk regenerasyon göstermiştir. En yüksek sayıda sürgün de 114 adet ile yine yalın ortamdan elde edilmiştir, ancak yalın ortam eksplant başına elde edilen ortalama sürgün sayısı bakımından 1.4 adet ile en az sürgün oluşturan ortam olmuştur. Yalın ortamı \%32 ile $0.5 \mathrm{mg} . \mathrm{I}^{-1}$ IAA içeren ortam takip etmiş olup kültüre alınan 50 eksplanttan 32 adedi direk rejenerasyon göstermiştir. $\mathrm{Bu}$ ortamda eksplant başına düşen ortalama sürgün sayısı ise 1.5 adet olarak gerçekleşmiştir. Direk rejenerasyon gösteren eksplantlardan elde edilen ortalama sürgün sayıları bakımından ise en yüksek başarı 2.6 adet ile 0.5 mg. $\mathrm{l}^{-1}$ BAP + $0.1 \mathrm{mg} \cdot \mathrm{l}^{-1}$ IAA içeren ortamdan elde edilmiştir. Ancak bu ortam $0.5 \mathrm{mg} . \mathrm{l}^{-1} \mathrm{BAP}+0.5 \mathrm{mg} . \mathrm{l}^{-1}$ IAA içeren ortamla beraber kültüre alınan eksplantlarda \%16 ile en az oranda direk jenerasyonun gözlendiği ortam olmuştur. İstatistiki anlamda direk rejenerasyon bakımından en iyi sonuç yalın besi ortamından elde edilirken araştırmaya konu diğer besi ortamları arasında direk rejenerasyon bakımından herhangi

Çizelge 3. Kültüre alınan hipokotil eksplantlarından elde edilen direk regenerasyon gösteren eksplant sayıları, başarı oranları (\%), elde edilen sürgün sayıları ve başarı ortalamalarına ilişkin veriler

\begin{tabular}{|c|c|c|c|c|c|c|c|}
\hline \multirow[b]{2}{*}{$\begin{array}{l}\text { Büyüme Düzenleyicisi } \\
\left(\mathrm{mg.l}^{-1}\right)\end{array}$} & \multirow[b]{2}{*}{$\begin{array}{l}\text { Eksplant } \\
\text { Sayısı } \\
\text { (Adet) }\end{array}$} & \multirow[b]{2}{*}{$\begin{array}{l}\text { Direk } \\
\text { Rejenerasyon } \\
\text { Gösteren } \\
\text { Eksplant } \\
\text { Sayısı** }\end{array}$} & \multirow[b]{2}{*}{$\begin{array}{l}\text { Başarı } \\
\text { Oranı } \\
(\%)\end{array}$} & \multicolumn{4}{|c|}{ Sürgün Oluşturma (Adet) } \\
\hline & & & & Köklü & Köksüz & Toplam & $\begin{array}{l}\text { Ekplant Başına Düşen } \\
\text { Ortalama Sürgün } \\
\text { Sayısı (Adet) }\end{array}$ \\
\hline $\mathrm{BAP}(0)+\operatorname{IAA}(0)$ & 50 & $42 \mathrm{a}$ & 84 & 27 & 30 & 57 & 1.4 \\
\hline $\operatorname{BAP}(0.5)+\operatorname{IAA}(0)$ & 50 & $11 \mathrm{~b}$ & 22 & 0 & 16 & 16 & 1.5 \\
\hline $\operatorname{BAP}(0)+\operatorname{IAA}(0.5)$ & 50 & $16 \mathrm{~b}$ & 32 & 8 & 16 & 24 & 1.5 \\
\hline $\operatorname{BAP}(0.5)+\operatorname{IAA}(0.5)$ & 50 & $8 \mathrm{~b}$ & 16 & 1 & 13 & 14 & 1.8 \\
\hline $\operatorname{BAP}(0.5)+\operatorname{IAA}(0.1)$ & 50 & $8 \mathrm{~b}$ & 16 & 1 & 20 & 21 & 2.6 \\
\hline $\operatorname{BAP}(0.1)+\operatorname{IAA}(0.5)$ & 50 & $9 \mathrm{~b}$ & 18 & 0 & 21 & 21 & 2.3 \\
\hline
\end{tabular}

**: 0,01 olasılık seviyesinde önemli 
bir fark gözlenmemiştir.

Daha önceden yapılan benzer çalışmalarda da bu çalışmaya benzer sonuçlar elde edilmiştir. Karamian ve Rajdar (2008), 2.4-D (2.4-dichlorophenoxyacetic acid) ve BAP, NAA (Naftalin Asetik Asit) ve BAP ile desteklenmiş ortamlarda en yüksek oranda somatik embriyogenesis yalın ortamdan elde ettiklerini bildirmişlerdir. Yine diğer bazı baklagil bitkilerinde de yalın ortamda yüksek oranlarda direk rejenerasyon ve kök oluşumları tespit edilmiştir (Luo ve Jia, 1998; Turgut, 2002). Nofouzi vd. (2019), BAP, IBA (İndol3-bütirik asit) ve TDZ (Thidiazuron) kullanarak yoncada yapmış oldukları çalışmada araştırmada kullandıkları her iki çeşit için de yalın ortamdan \%100 oranında direk rejenerasyon elde etmişlerdir. Bununla birlikte bazı araştırmacılar yapmış oldukları çalışmalarda en yüksek direk sürgün rejenerasyonunu farklı hormonları içeren besi ortamlarından elde ettiklerini bildirmişlerdir. Yıldız ve Ekiz (2014), yapmış oldukları çalışmada korunga bitkisinin hipokotil eksplantlarını kullanmışlar ve farklı sıcaklık derecelerinde en yüksek sürgün oluşumunu $0.5 \mathrm{mg} . \mathrm{l}^{-1} \mathrm{BAP}$ + 0.02 mg. $\mathrm{l}^{-1} \mathrm{NAA}$ ve $0.5 \mathrm{mg} \cdot \mathrm{l}^{-1} \mathrm{BAP}+0.2 \mathrm{mg} \cdot \mathrm{l}^{-1} \mathrm{NAA}$ içeren ortamlardan elde ettiklerini bildirmişlerdir. Mohajer vd. (2012), 0, 0.5, 1, 1.5, 2, 2.5 ve 3 mg. $\mathrm{l}^{-1}$ oranlarında BAP, NAA ve IBA içeren MS ortamında yapmış oldukları çalışmada en yüksek oranda direk rejenerasyonu gövde

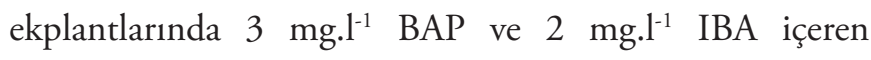
ortamdan, yaprak eksplantlarında ise $0.5 \mathrm{mg}^{-1}{ }^{-1} \mathrm{BAP}$ ve 2.5 mg. ${ }^{1-1}$ IBA içeren ortamdan elde ettiklerini bildirmişlerdir. Ancak bu araştırmacılar çalışmalarında yalın besi ortamına yer vermemişlerdir.

Kültüre alınan hipokotil eksplantlarından elde edilen kallus sayıları ve kalluslardan elde edilen sürgün, bitki sayılarına ve başarı oranlarına ilişkin veriler Çizelge 4’te verilmiştir.

Araştırmaya konu besi ortamlarında kültüre alınan eksplantlardan en yüksek oranda kallus $\% 84$ ile 0.5 mg. ${ }^{1-1}$ BAP + 0.1 mg. $l^{-1}$ IAA içeren besi ortamından elde edilmiştir. Bu ortam $1 \% 82$ ile $0.1 \mathrm{mg} . \mathrm{l}^{-1} \mathrm{BAP}+0.5 \mathrm{mg}^{-\mathrm{l}^{-1}} \mathrm{IAA}$ içeren besi ortamı takip etmiştir. Bu iki ortam arasında istatistiksel anlamda bir fark tespit edilmemiştir. En az sayıda kallus ise \%10 ile yalın besi ortamından elde edilmiştir (Çizelge 4). Oluşan kullauslardan elde edilen kallus başına düşen ortalama sürgün sayıları bakımından en yüksek başarı 0.83 adet ile $0.5 \mathrm{mg} . \mathrm{l}^{-1} \mathrm{BAP}$ içeren ortamdan elde edilmiştir. Bu ortam 10.43 adet ile $0.5 \mathrm{mg} . \mathrm{l}^{-1}$ IAA içeren ortam ve0.30 adet ile yalın ortam takip etmiştir. $0.5 \mathrm{mg} . \mathrm{l}^{-1} \mathrm{BAP}+0.5$ mg..$^{1-1}$ IAA, 0.5 mg..$^{-1}$ BAP + 0.1 mg..$^{-1}$ IAA ve $0.1 \mathrm{mg} . .^{-1}$ $\mathrm{BAP}+0.5 \mathrm{mg} . \mathrm{l}^{-1} \mathrm{IAA}$ içeren ortamlardan diğer ortamlara kıyasla daha yüksek oranda kallus elde edilmesine rağmen bu ortamlarda sürgün rejenerasyonu gözlenmemiştir.

Çizelge 4. Kültüre alınan hipokotil eksplantlarından elde edilen kallus sayıları ve kalluslardan elde edilen sürgün, bitki sayılarına ve başarı oranlarına ilişkin veriler

\begin{tabular}{|c|c|c|c|c|c|c|c|}
\hline \multirow[b]{2}{*}{$\begin{array}{l}\text { Büyüme Düzenleyicisi } \\
\left(\mathrm{mg.l}^{-1}\right)\end{array}$} & \multirow[b]{2}{*}{$\begin{array}{l}\text { Eksplant } \\
\text { Sayısı } \\
\text { (Adet) }\end{array}$} & \multicolumn{2}{|c|}{ Kallus Oluşumu** } & \multicolumn{4}{|c|}{ Kallustan Sürgün Oluşumu } \\
\hline & & Adet & $\begin{array}{l}\text { Başarı } \\
\text { oranı }(\%)\end{array}$ & Köklü & Köksüz & Toplam & $\begin{array}{l}\text { Kallus Başına } \\
\text { Ort. Sürgün } \\
\text { Sayısı }\end{array}$ \\
\hline $\mathrm{BAP}(0)+\operatorname{IAA}(0)$ & 50 & $5 \mathrm{c}$ & 10 & 0 & 3 & 3 & 0.30 \\
\hline $\mathrm{BAP}(0.5)+\operatorname{IAA}(0)$ & 50 & $21 \mathrm{bc}$ & 42 & 0 & 35 & 35 & 0.83 \\
\hline $\mathrm{BAP}(0)+\operatorname{IAA}(0.5)$ & 50 & $30 \mathrm{ab}$ & 60 & 10 & 16 & 26 & 0.43 \\
\hline $\operatorname{BAP}(0.5)+\operatorname{IAA}(0.5)$ & 50 & $32 \mathrm{ab}$ & 64 & 0 & 0 & 0 & 0.00 \\
\hline $\operatorname{BAP}(0.5)+\operatorname{IAA}(0.1)$ & 50 & $42 \mathrm{a}$ & 84 & 0 & 0 & 0 & 0.00 \\
\hline $\mathrm{BAP}(0.1)+\operatorname{IAA}(0.5)$ & 50 & $41 \mathrm{a}$ & 82 & 0 & 0 & 0 & 0.00 \\
\hline
\end{tabular}

**: 0,01 olasılık seviyesinde önemli 
Araştırmaya konu besi ortamlarında kültüre alınan eksplantlardan elde edilen hem direk rejenerasyon hem de kallus oluşumları dikkate alınarak hesaplanan genel başarı oranları (\%) Çizelge 5'te varyans analiz sonuçları Çizelge 6'da verilmiştir.

Besi ortamlarında kültüre alınan eksplantlardan elde edilen genel başarı oranları incelendiğinde en yüksek başarı oranı \% 100 ile $0.5 \mathrm{mg} \cdot \mathrm{l}^{-1} \mathrm{BAP}+0.1 \mathrm{mg} . \mathrm{l}^{-1} \mathrm{IAA}$ ve $0.1 \mathrm{mg} \cdot \mathrm{l}^{-1} \mathrm{BAP}$
(Hatipoğlu, 2012). Bu çalışmada tek bir genotip kullanılmış olup farklı konsantrasyonda hormon içeren besi ortamlarında korunganın rejenerasyon yeteneğinin belirlenmesi amaçlanmıştır. Bitki doku kültürlerinde besi ortamının bileşimi başarıyı etkileyen en önemli faktörlerin başında gelmektedir. Farklı tipteki eksplantlardan korunga sürgünü rejenerasyonu ortam koşullarının değiştirilmesi yoluyla başarılabilmiştir (Özcan vd., 1996; Sancak, 1999; Mohajer vd., 2012; Yıldız ve Ekiz, 2014; Uzun ve

Çizelge 5. Besi ortamlarına göre genel başarı oranları (\%)

\begin{tabular}{|c|c|c|c|c|c|}
\hline $\begin{array}{l}\text { Büyüme Düzenleyicisi } \\
\left(\mathrm{mg.l^{-1 }}\right)\end{array}$ & $\begin{array}{l}\text { Kültüre } \\
\text { Alınan } \\
\text { Eksplant } \\
\text { Sayısı (Adet) }\end{array}$ & $\begin{array}{l}\text { Toplam Direk } \\
\text { Rejenere Olan } \\
\text { Eksplant Sayısı } \\
\text { (Adet) }\end{array}$ & $\begin{array}{l}\text { Toplam Kallus } \\
\text { Oluşturan } \\
\text { Eksplant } \\
\text { Sayısı }\end{array}$ & $\begin{array}{l}\text { Toplam } \\
\text { Regenerasyon } \\
\text { Gösteren Eksplant } \\
\text { Sayısı** }\end{array}$ & $\begin{array}{l}\text { Genel Başarı } \\
\text { Oranı } \\
(\%)\end{array}$ \\
\hline $\mathrm{BAP}(0)+\operatorname{IAA}(0)$ & 50 & 42 & 5 & $47 \mathrm{ab}$ & 94 \\
\hline $\operatorname{BAP}(0.5)+\operatorname{IAA}(0)$ & 50 & 11 & 21 & $32 \mathrm{c}$ & 64 \\
\hline $\mathrm{BAP}(0)+\operatorname{IAA}(0.5)$ & 50 & 16 & 30 & $46 \mathrm{ab}$ & 92 \\
\hline $\operatorname{BAP}(0.5)+\operatorname{IAA}(0.5)$ & 50 & 8 & 32 & $40 \mathrm{~b}$ & 80 \\
\hline $\operatorname{BAP}(0.5)+\operatorname{IAA}(0.1)$ & 50 & 8 & 42 & $50 \mathrm{a}$ & 100 \\
\hline $\operatorname{BAP}(0.1)+\operatorname{IAA}(0.5)$ & 50 & 9 & 41 & $50 \mathrm{a}$ & 100 \\
\hline
\end{tabular}

**: 0,01 olasılık seviyesinde önemli

\begin{tabular}{lllll}
\hline Özellik & SD & Standart Hata & Grup Ortalamasi & F değerleri \\
\hline Direk Rejenerasyon & 29 & 0,561 & 3,13 & $8,594^{* *}$ \\
Kallus Oluşumu & 29 & 0,629 & 5,70 & $6,073^{* *}$ \\
Toplam Rejenerasyon & 29 & 0,304 & 8,83 & $7,533^{* *}$ \\
\hline
\end{tabular}

**: 0,01 olasılık seviyesinde önemli

+ $0.5 \mathrm{mg} . \mathrm{l}^{-1}$ IAA içeren besi ortamından elde edilmiştir. Bu ortamı \%94 başarı oranı ile yalın besi ortamı, \%92 ile 0.5 mg. $1^{-1}$ IAA içeren besi ortamı takip etmiştir. Ancak bu 4 besi ortamı arasında istatistiki anlamda fark tespit edilmemiştir. Genel başarı oranı bakımından en düşük başarı oranı ise \%64 başarı oranı ile 0.5 mg. $\mathrm{l}^{-1}$ BAP içeren ortamdan elde edilmiştir. $\mathrm{Bu}$ ortam istatistiksel anlamda da en düşük başarı gösteren besi ortamını oluşturmuştur.

Bitki doku kültürü çalışmalarında organogenesis yoluyla gerçekleştirilen bitki rejenerasyonu; genotip, besi ortamı, eksplant kaynakları, eksplant yaşı, ortam bileşimi ve çevresel koşullar gibi çeşitli faktörlerden etkilenmektedir
Yükselgüngör, 2020). Bizim çalışmamıza benzer olarak yapılan birçok çalışmada da sitokinin (BAP, Kinetin gibi) ve oksin (IAA, NAA, IBA gibi) hormonlarının birlikte kullanılması kallus oluşumunu teşvik ettiği belirlenmiştir. Yine bizim çalışmamıza benzer olarak besi ortamında BAP hormon konsantrasyonunun yüksek olması kallus oluşumuna sebebiyet vermiştir. Sancak (1999), BAP, IBA, NAA hormonlarını kullanarak yapmış olduğu çalışmada en yüksek sürgün oluşumunu $2 \mathrm{mg} \cdot \mathrm{l}^{-1} \mathrm{BAP}$ ile IBA'in 0.05, 0.1 ve $0.5 \mathrm{mg} . \mathrm{l}^{-1}$ lik ortamlarından veya $8 \mathrm{mg} . \mathrm{l}^{-1} \mathrm{BAP}$ ile $0,05 \mathrm{mg} \cdot \mathrm{l}^{-1} \mathrm{NAA}$ içeren ortamdan elde ettiğini bildirmiştir. Mohajer vd. (2012), 0, 0.5, 1, 1.5, 2, 2.5 ve 3 mg.1 ${ }^{-1}$ oranlarında BAP, NAA ve IBA içeren MS ortamında yapmış 
oldukları çalışmada yaprak eksplantlarından en yüksek oranda kallus oluşumunu 2 ve 3 mg..$^{-1}$ sadece BAP içeren ortamdan elde ettiklerini, optimum düzeyde embriyogenik kallus oluşumunu $2.5 \mathrm{mg}^{-1}{ }^{-1}$ BAP ve $0.5 \mathrm{mg} .1^{-1} \mathrm{NAA}$ içeren ortamdan elde ettiklerini bildirmişleridir. Kök eksplantlarında ise BAP içeren bütün ortamların yüksek oranda kallus oluşturduklarını bildirmişlerdir. Mohajer vd. (2014), 0-2.0 mg mg..$^{-1}$ kinetin ve 0-2.0 mg mg..$^{-1}$ IAA kullanarak yapmış oldukları çalışmada en yüksek kallus oluşumunu gövde eksplantlarında $0.5 \mathrm{mg}^{-1}{ }^{-1}$ kinetin ve 1.5 mg. $l^{-1}$ IAA içeren ortamdan, yaprak eksplantlarında ise en yüksek kallus oluşumunu $0.5 \mathrm{mg} . \mathrm{l}^{-1}$ kinetin ve $1.5 \mathrm{mg} . \mathrm{l}^{-}$ ${ }^{1}$ IAA ve sadece $1.5 \mathrm{mg} . \mathrm{l}^{-1}$ kinetin içeren ortamdan elde etiklerini bildirmişlerdir.

\section{SONUÇ}

$\mathrm{Bu}$ araştırmada Özerbey-03 korunga çeşidi kullanılarak korunga hipokotil ekplantlarından bitki rejenerasyonu üzerine BAP (sitokinin hormonu) ve IAA (oksin hormonu) hormonlarının etkisi araştırılmıştır. Araştırma neticesinde direk rejenerasyon bakımından hiçbir hormon kullanılmayan yalın ortamının, kallus oluşumu bakımından ise $0.5 \mathrm{mg} . \mathrm{l}^{-1} \mathrm{BAP}+0.1 \mathrm{mg} \cdot \mathrm{l}^{-1} \mathrm{IAA}$ içeren ortamın, besi ortamları toplam rejenerasyon bakımından değerlendirildiğinde ise en iyi sonucu $0.5 \mathrm{mg}^{-l^{-1}} \mathrm{BAP}+$ $0.1 \mathrm{mg} . \mathrm{l}^{-1} \mathrm{IAA}, 0.1 \mathrm{mg} . \mathrm{l}^{-1} \mathrm{BAP}+0.5 \mathrm{mg} . \mathrm{l}^{-1} \mathrm{IAA}$ içeren besi ortamlarının verdiği belirlenmiştir. Yine kalluslardan sürgün rejenerasyonu bakımından en iyi sonuç $0.5 \mathrm{mg} .1$ 1 BAP içeren ortamdan elde edilmiştir. Bu çalışmanın sonuçlarına göre korunga hipokotil eksplantlarından direk sürgün rejenerasyonu için hormon içermeyen besi ortamlarının tercih edilmesi, kallus oluşumu arzu ediliyorsa yüksek konsantrasyonda BAP (veya başka bir sitokinin hormonu) içeren veya oksin ve sitokinini birlikte içeren ortamların tercih edilmesi yararlı olacaktır. Tabiki doku kültürü çalışmalarında kullanılan genotip, besi ortamının bileşimi ve diğer fiziksel ve kimyasal faktörlerin de etkili olduğu unutulmamalıdır. Daha kesin sonuçlar için farklı tipte ve farklı konsantrasyonda oksin ve sitokinin hormonları kullanılarak ve farklı çeşit veya genotiplerle benzer çalışmaların yürütülmesi isabetli olacaktır.

\section{TEŞEKKÜR}

$\mathrm{Bu}$ çalışma lisans tez ürünüdür. Araştırmada kullanılan Özerbey-03 çeşidine ait tohumları bizlere temin eden Tarım İşletmeleri Genel Müdürlüğü (TİGEM)'ne teşekkür ederiz.

\section{KAYNAKLAR}

Anonim, 2021. Türkiye Bitkileri Veri Serisi (TÜBİVES). http://www.tubives.com/. Erişim Tarihi: 14.02.2021. Beyaz, R., 2014. Farklı Korunga (Onobrychis viciifolia Scop.) Ekotiplerinin Tuza Toleransının Belirlenmesi ve In vitro Mutagenesis Tekniği Aracilığıyla Yeni Korunga

Hatlarının Geliştirilmesi. Ankara Üniversitesi, Biyoteknoloji Enstitüsü, Temel Biyoteknoloji, Yüksek Lisans Tezi, 382402.

Boissier, E., 1872. Flora Orientalis. Vol. 2, p 35, Geneve. Hatipoğlu, R., 2012. Bitki Biyoteknolojisi. Ders Kitabı, Çukurova Üviversitesi, Ziraat Fakültesi, Tarla Bitkileri Bölümü, No:176, Adana.

Hedge, I.C., 1970, Hedysarum L. in Davis, P.H. Flora of Turkey and the East Aegean Islands Vol.3: 549-560. -Edinburgh.

İleri, O., 2014. Türkiye de Doğal Olarak Yetişen Onobrychis Seksiyonuna Ait Bazı Endemik Korunga Türlerinin Karyolojik Özellikleri. Eskişehir Osmangazi Üniversitesi, Fen Bilimleri Enstitüsü, Tarla Bitkileri Anabilim Dalı, Yüksek Lisans Tezi, 382613.

Karamian, R., Ranjbar, M., 2008. Plant regeneration from Onobrychis subnitens Bornm. Hypocotyl explants via somatic embryogeness and organogenesis. Acta Biologica Cracoviensia, Series Botanica, 50/2: 13-18. Kurt, O., 2015. Bitki Islahı. Konu 8. Hücre ve Doku Kültürü. Ondokuz Mayıs Üniversitesi, Ziraat Fakültesi. Ders Kitabı No:43. Sf.165.

Luo, J.P., Jia, J.F. 1998. Callus induction and plant regeneration from hypocotyl explants of the forage legume Astragalus adsurgens. Plant Cell Reports, 17: $567-570$.

Mohajer, S., Mat Taha, R., Mohajer, M., Khorasani Esmaeili, A., 2014. Micropropagation of bioencapsulation and ultrastructural features of sainfoin (Onobrychis viciifolia) grown in vivo and in vitro. The Scientific World Journal, 1: 64-73. 
Mohajer, S., Taha, R.M., Khorasani, A., Yaacob, J.S., 2012. Induction of different types of callus and somatic embryogenesis in various explants of Sainfoin (Onobrychis sativa). Australian Journal of Crop Science, 6:1305-13.

Nofouzi, F., Oğuz, M.Ç., Khabbazi, S.D., Ergül, A., 2019. Improvement of the in vitro regeneration and Agrobacterium-mediated genetic transformation of Medicago sativa L. Turkish Journal of Agriculture and Forestry, 43: 96-104.

Özbek, H., 2011. Korunga (Onobrychis viciifolia Scop.) Önemli Bir Arı Bitkisi. Ar1 Bilimi, 11(2): 51-62.

Özcan, S., Sevimay, C.S., Yıldız, M., Sancak, C., Özgen, M. 1996. Prolific shoot regeneration from immature embryo explants of sainfoin (Onobrychis viciifolia Scop.). Plant Cell Report, 16:200- 203.

Sancak, C., 1999. In vitro Micropropagation of Sainfoin (Onobrychis viciifolia Scop.), Tukish Journal of Botany, 23, 133-136.

Turgut, N., 2002. Astragalus türlerinde doku kültürü çalışmaları. İstanbul Üniversitesi Fen Bilimleri Ensitüsü, Biyoloji A.B.D, Yüksek Lisans Tezi

Uzun, S., Yükselgüngör, D., 2020. Micropropagation of some onobrychis species through in vitro shoot regeneration. Acta Scientiarum Polonorum Hortorum Cultus. Vol.19 No.5 pp.45-52.

Yildiz, M., Ekiz, H., 2014. The effect of sodium hypochlorite solutions on in vitro seedling growth and regeneration capacity of sainfoin (Onobrychis viciifolia Scop.) hypocotyl explants. Canadian Journal of Plant Science, 94:1161-1164.

Yücel, G., 2019. Kültürü Yapılan Korunga (Onobrychis Mill., Baklagiller) Taksonları ve Bazı Yabani Akrabalarının Moleküler Sitogenetik Yöntemler ile Karakterizasyonu. Tekirdağ Namık Kemal Üniversitesi, Fen Bilimleri Enstitüsü, Biyoloji Anabilim Dalı, Doktora Tezi. 